\title{
Homogeneous nucleation of NAD and NAT in liquid stratospheric aerosols: insufficient to explain denitrification
}

\author{
D. A. Knopf, T. Koop, B. P. Luo, U. G. Weers, and T. Peter \\ Institute for Atmospheric and Climate Science, Swiss Federal Institute of Technology, Zurich, Switzerland \\ Received: 18 April 2002 - Published in Atmos. Chem. Phys. Discuss.: 12 June 2002 \\ Revised: 19 August 2002 - Accepted: 20 August 2002 - Published: 30 August 2002
}

\begin{abstract}
The nucleation of NAD and NAT from $\mathrm{HNO}_{3} / \mathrm{H}_{2} \mathrm{O}$ and $\mathrm{HNO}_{3} / \mathrm{H}_{2} \mathrm{SO}_{4} / \mathrm{H}_{2} \mathrm{O}$ solution droplets is investigated both theoretically and experimentally with respect to the formation of polar stratospheric clouds (PSCs). Our analysis shows that homogeneous NAD and NAT nucleation from liquid aerosols is insufficient to explain the number densities of large nitric acid containing particles recently observed in the Arctic stratosphere. This conclusion is based on new droplet freezing experiments employing optical microscopy combined with Raman spectroscopy. The homogeneous nucleation rate coefficients of NAD and NAT in liquid aerosols under polar stratospheric conditions derived from the experiments are $<2 \times 10^{-5} \mathrm{~cm}^{-3} \mathrm{~s}^{-1}$ and $<8 \times 10^{-2} \mathrm{~cm}^{-3} \mathrm{~s}^{-1}$, respectively. These nucleation rate coefficients are smaller by orders of magnitude than the value of $\sim 10^{3} \mathrm{~cm}^{-3} \mathrm{~s}^{-1}$ used in a recent denitrification modelling study that is based on a linear extrapolation of laboratory nucleation data to stratospheric conditions (Tabazadeh et al., Science, 291, 2591-2594, 2001). We show that this linear extrapolation is in disagreement with thermodynamics and with experimental data and, therefore, must not be used in microphysical models of PSCs. Our analysis of the experimental data yields maximum hourly production rates of nitric acid hydrate particles per $\mathrm{cm}^{3}$ of air of about $3 \times 10^{-10} \mathrm{~cm}^{-3}$ (air) $\mathrm{h}^{-1}$ under polar stratospheric conditions. Assuming PSC particle production to proceed at this rate for two months we arrive at particle number densities of $<5 \times 10^{-7} \mathrm{~cm}^{-3}$, much smaller than the value of $\sim 10^{-4} \mathrm{~cm}^{-3}$ reported in recent field observations. In addition, the nitric acid hydrate production rate inferred from our data is much smaller than that required to reproduce the observed denitrification in the modelling study mentioned above. This clearly shows that homogeneous nucleation of NAD and NAT from liquid supercooled ternary solution
\end{abstract}

Correspondence to: D. A. Knopf

(Daniel.Knopf@atmos.umnw.ethz.ch) aerosols cannot explain the observed polar denitrification.

\section{Introduction}

Polar stratospheric cloud (PSC) particles activate chlorine from reservoir to reactive species by heterogeneous reactions on their surfaces. Field measurements have shown that PSCs can be composed of liquid supercooled ternary solutions (STS) and nitric acid trihydrate (NAT) (Schreiner et al., 1999; Voigt et al., 2000). In addition, nitric acid dihydrate (NAD) has been suggested to exist in PSCs based on laboratory experiments (Worsnop et al., 1993). Large $\mathrm{HNO}_{3}$-containing PSC particles can lead to significant denitrification of the polar stratosphere by sedimentation (Fahey et al., 2001). However, the mechanisms of how such large particles come about have not yet been established (Tolbert and Toon, 2001). It has been suggested that large nitric acid hydrate particles leading to denitrification could be produced by homogeneous nucleation of NAD and NAT from liquid STS (Tabazadeh et al., 2001), based on an extrapolation of laboratory aerosol nucleation data (Salcedo et al., 2001) to stratospheric conditions. However, the employed extrapolation is in disagreement with bulk nucleation experiments performed at stratospheric conditions (Koop et al., 1997). For example, according to the nucleation formulation an aqueous ternary solution of $41.2 \mathrm{wt} \% \mathrm{HNO}_{3}$ and $3.9 \mathrm{wt} \% \mathrm{H}_{2} \mathrm{SO}_{4}$ and $1 \mathrm{~cm}^{3}$ in volume is predicted to freeze at $249.0 \mathrm{~K}$. In contrast, in experiments such samples did not freeze down to temperatures of $190 \mathrm{~K}$ (Koop et al., 1995). Also, the formulation is in disagreement with aerosol experiments of aqueous nitric acid solutions (Bertram and Sloan, 1998a,b; Bertram et al., 2000; Salcedo et al., 2001). To resolve these inconsistencies we investigate here the nucleation kinetics of NAD and NAT in liquid binary $\mathrm{HNO}_{3} / \mathrm{H}_{2} \mathrm{O}$ and ternary $\mathrm{HNO}_{3} / \mathrm{H}_{2} \mathrm{SO}_{4} / \mathrm{H}_{2} \mathrm{O}$ solutions both theoretically and experimentally. First, we reexamine the physics of the ni- 


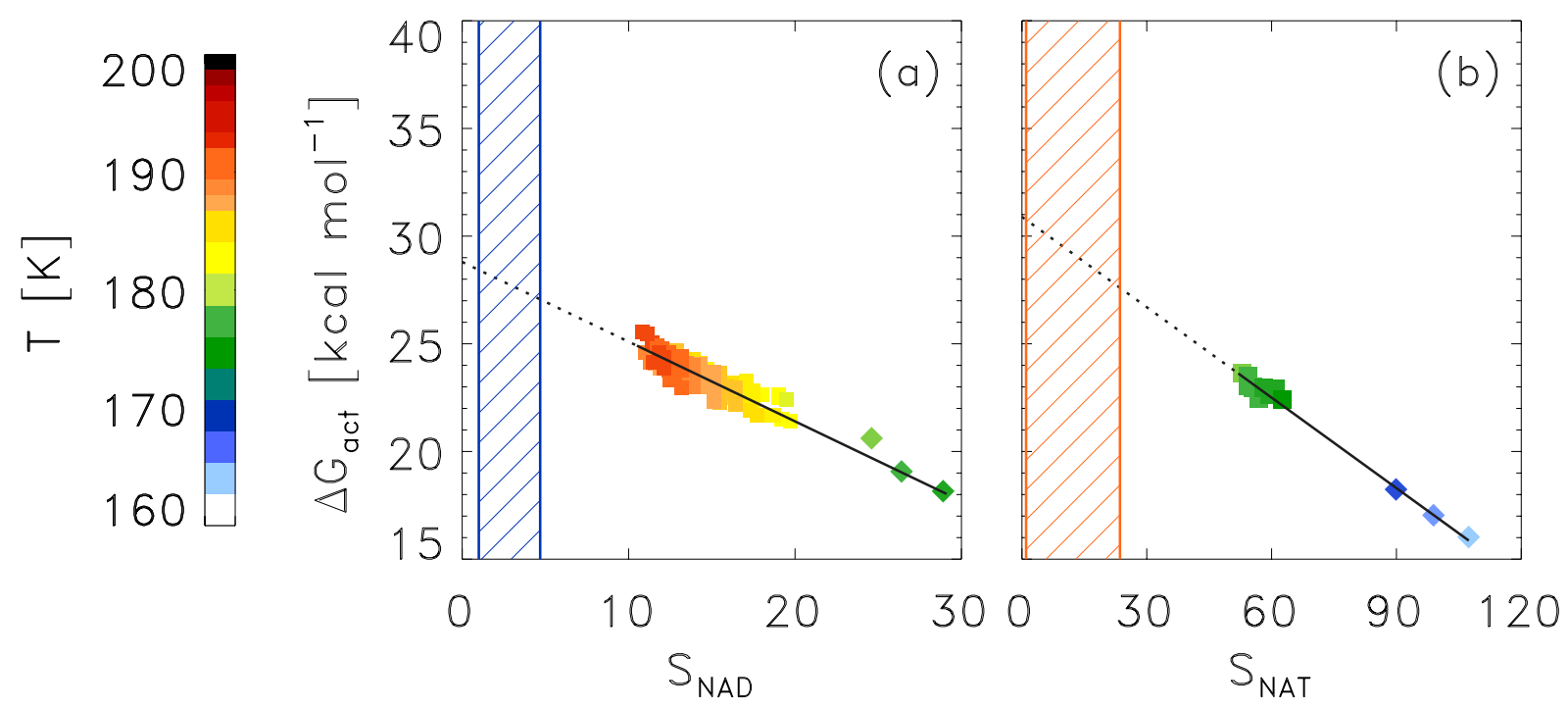

Fig. 1. $\Delta G_{\text {act }}$ as function of the NAD and NAT saturation ratios derived from laboratory nucleation data using Eq. (3) (Salcedo et al., 2001). All data points were derived from experiments with droplets consisting of binary aqueous nitric acid solutions of varying composition. (a) $\mathbf{a}$ : $57 \mathrm{wt} \%, 60 \mathrm{wt} \%$, and $64 \mathrm{wt} \% \mathrm{HNO}_{3}$ (Salcedo et al., 2001); $\$$ : $64 \mathrm{wt} \% \mathrm{HNO}_{3}$ (Bertram and Sloan, 1998a). (b) ם: $54 \mathrm{wt} \% \mathrm{HNO}$ (Salcedo et al., 2001); $54 \mathrm{wt} \% \mathrm{HNO}_{3}$ (Bertram and Sloan, 1998b). The color coding indicates at which temperature the data were obtained. The shaded regions indicate typical NAD and NAT saturation ratios at polar stratospheric conditions. The solid lines show the linear relationship between $\Delta G_{\text {act }}$ and $S_{\mathrm{NAX}}$ observed by Salcedo et al. (2001), and the dotted lines are the linear extrapolations to stratospheric conditions used in Tabazadeh et al. (2001).

tric acid hydrate nucleation formulation used by Tabazadeh et al. (2001). Second, we present new experimental data on NAD and NAT nucleation from STS droplets under stratospheric conditions. Third, we use these data together with previously published data sets to deduce upper limits of homogeneous nucleation rate coefficients of NAD and NAT. Finally, from the inferred nucleation rate coefficients we derive maximum production rates of solid nitric acid particles under polar stratospheric conditions.

\section{Nucleation formulation analysis}

Salcedo et al. (2001) and Tabazadeh et al. (2001) have employed classical nucleation theory to describe the experimentally observed homogeneous nucleation rate coefficients, $J_{\text {hom }}$, of nitric acid hydrates (NAX; $\mathrm{X}=\mathrm{D}$ or T):

$J_{\text {hom }}(T)=n_{\text {liq }}\left(\frac{k T}{h}\right) \exp \left[\frac{-\Delta G_{\text {act }}(T)}{R T}\right]$,

where $n_{\text {liq }}$ is the $\mathrm{HNO}_{3}$ molecular number density in the liquid, $R$ is the universal gas constant, $k$ is the Boltzmann constant, and $h$ is the Planck constant. $\Delta G_{\text {act }}$ is the activation energy required to form a critical cluster in the solution. According to classical nucleation theory this activation energy depends on the saturation ratio of the respective nitric acid hydrate $\left(S_{\mathrm{NAX}}\right)$ :

$\Delta G_{\text {act }}(T)=\frac{16}{3} \pi \sigma_{s l}^{3}(T)\left[\frac{v_{\text {sol }}}{R T \ln \left(S_{\mathrm{NAX}}\right)}\right]^{2}+\Delta G_{\mathrm{dif}}(T)$
Here, $\sigma_{s l}$ is the interfacial tension between the solid and liquid phase, $v_{\text {sol }}$ is the molar volume of NAX in the critical cluster, and $\Delta G_{\text {dif }}$ is the $\mathrm{HNO}_{3}$ diffusion activation energy across the boundary between the cluster and the solution. Since measured values for $\sigma_{s l}$ and $\Delta G_{\text {dif }}$ are not available (MacKenzie, 1997), $\Delta G_{\text {act }}$ can be determined from experimentally observed nucleation rate coefficients by solving Eq. (1) for $\Delta G_{\text {act }}$ :

$\Delta G_{\text {act }}(T)=-R T \ln \left[\frac{h}{k T} \frac{J_{\text {hom }}(T)}{n_{\text {liq }}}\right]$

Figure 1 shows values of $\Delta G_{\text {act }}$ in aqueous nitric acid solutions as plotted by Salcedo et al. (2001) as function of the NAD and NAT saturation ratio derived from their experimental data using Eq. (3). The laboratory data reveal a linear relationship between $\Delta G_{\text {act }}$ and $S_{\mathrm{NAX}}$ (solid lines in Fig. 1) in the experimentally observed range of saturation ratios $\left(S_{\mathrm{NAD}}=11-30, S_{\mathrm{NAT}}=52-107\right)$. Since stratospheric saturation ratios (shaded areas in Fig. 1) are much smaller than the experimentally investigated range, Tabazadeh et al. (2001) used a linear extrapolation (dotted lines in Fig. 1) to infer $\Delta G_{\text {act }}{ }^{-}$ values for NAD and NAT at stratospheric conditions. However, applying such an extrapolation is physically unreasonable because according to Eq. (2), $\Delta G_{\text {act }}$ increases towards infinity for $S_{\mathrm{NAX}}$ approaching unity. In contrast, the linear extrapolation leads to a $\Delta G_{\text {act }}$-value of about $30 \mathrm{kcal} \mathrm{mol}^{-1}$ in each case. Note, that an underestimation of $\Delta G_{\text {act }}$ by $1 \mathrm{kcal} \mathrm{mol}^{-1}$ increases the corresponding homogeneous 

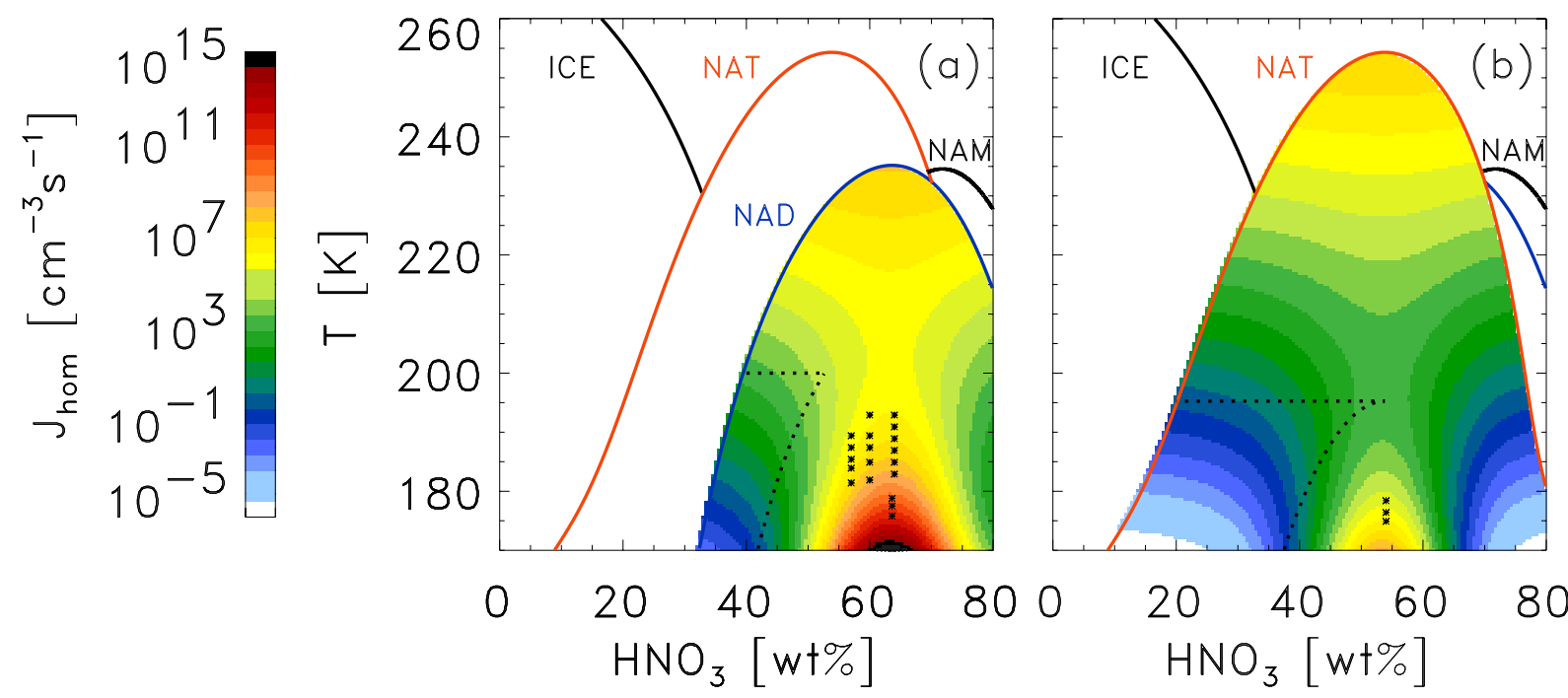

Fig. 2. Homogeneous nucleation rate coefficients of NAD (a) and NAT (b) in binary $\mathrm{HNO}_{3} / \mathrm{H}_{2} \mathrm{O}$ solutions as function of temperature and concentration using the formulation of Tabazadeh et al. (2001). Solid lines show the melting point curves of the different solid phases $(S=1)$. The regions between dotted and solid lines indicate typical polar stratospheric temperatures $(\leq 200 \mathrm{~K})$ and saturation ratios $(\leq 4.7$ for NAD and $\leq 23.5$ for NAT). Black asterisks correspond to the experimental data shown in Fig. 1.

nucleation rate coefficient by a factor of 14 . Therefore, the linear extrapolation underestimates $\Delta G_{\text {act }}$ and, consequently, largely overestimates the homogeneous nucleation rate coefficient at low saturation ratios. In Fig. 2 we elucidate the effects of the linear extrapolation on the homogeneous nucleation rate coefficients of NAD and NAT in aqueous nitric acid solutions. The nucleation formulation produces finite nucleation rate coefficients along the NAD and NAT melting point curves (where $S_{\mathrm{NAX}}=1$ ) and does so even for values of $S_{\text {NAX }}<1$ (not shown in Fig. 2). This is thermodynamically impossible for any spontaneous process, since the formation of an unstable crystal (similar to nucleating ice above $273.15 \mathrm{~K}$ ) would lead to an increase of the total Gibbs free energy of the system. This nucleation formulation produces unrealistically high nucleation rate coefficients of about $10^{8} \mathrm{~cm}^{-3} \mathrm{~s}^{-1}$ at the top of the NAD and NAT melting curves (dark yellow region at $T=230 \mathrm{~K}$ in Fig. 2a and $T=250 \mathrm{~K}$ in Fig. 2b) in disagreement with numerous experimental studies (Anthony et al., 1997; Koop et al., 1997; Bertram and Sloan, 1998a,b; Bertram et al., 2000; Salcedo et al., 2001). In addition, at stratospheric temperatures (180$200 \mathrm{~K}$ ) and saturation ratios (between the solid and dotted lines in Fig. 2) the homogeneous nucleation rate coefficient increases with temperature. This behavior is due to the fact that in the formulation $\Delta G_{\text {act }}$ depends solely on $S_{\mathrm{NAX}}$, independently of the temperature (Tabazadeh et al., 2001, note 21). Only in the proximity of the experimental data (black asterisks in Fig. 2) a reasonable temperature and concentration dependency of $J_{\text {hom }}$ is observed. We conclude that the linear relationship between $\Delta G_{\text {act }}$ and $S_{\mathrm{NAX}}$ should not be used outside the range of available experimental data and, therefore, should not be extrapolated to stratospheric conditions.

\section{Experimental}

Freezing experiments with $\mathrm{HNO}_{3} / \mathrm{H}_{2} \mathrm{O}$ and $\mathrm{HNO}_{3} / \mathrm{H}_{2} \mathrm{SO}_{4} / \mathrm{H}_{2} \mathrm{O}$ droplets were performed in order to determine homogeneous nucleation rate coefficients of NAD and NAT at stratospheric saturation ratios. We chose to investigate large droplets $(0.12-0.27 \mathrm{~cm}$ in diameter) because smaller droplets $\left(2 \times 10^{-5}-8.5 \times 10^{-3} \mathrm{~cm}\right.$ in diameter $)$ do not freeze at stratospheric temperatures and saturation ratios (Anthony et al., 1997; Bertram and Sloan, 1998a,b; Bertram et al., 2000; Salcedo et al., 2001). The droplets were deposited with a micropipette on a hydrophobically coated quartz plate inside a laminar flow clean bench. Either a Teflon plate or an o-ring, each covered by a thin layer of high-vacuum-grease, served as a spacer for a second quartz plate which sealed the droplets against ambient air. The inner diameter of the spacer depended on the investigated droplet volume and varied between $0.3-0.6 \mathrm{~cm}$ and the spacer thickness ranged between $0.125-0.175 \mathrm{~cm}$. The total volume of the cell was about $8.8 \times 10^{-3}-5 \times 10^{-2} \mathrm{~cm}^{3}$. The volume of the droplets varied between $10^{-3}-10^{-2} \mathrm{~cm}^{3}$. Therefore, even at room temperature the number of water and $\mathrm{HNO}_{3}$ molecules in the gas phase of the cell is negligible when compared to the number of condensed water and $\mathrm{HNO}_{3}$ molecules in the droplets. Hence, the composition of the droplets stays constant during a freezing experiment. The preparation of the droplet cell took about $15 \mathrm{~s}$. The 
Table 1. Composition, volume, total number of performed experiments, and total number of individual droplets. The symbols refer to the ones in Fig. 5

\begin{tabular}{cccccccc}
\hline Solution & $\begin{array}{c}\mathrm{HNO}_{3} \\
{[\mathrm{wt} \%]}\end{array}$ & $\begin{array}{c}\mathrm{H}_{2} \mathrm{SO}_{4} \\
{[\mathrm{wt} \%]}\end{array}$ & $\begin{array}{c}\mathrm{H}_{2} \mathrm{O} \\
{[\mathrm{wt} \%]}\end{array}$ & $\begin{array}{c}\text { Volume } \\
{\left[10^{-3} \mathrm{~cm}^{-3}\right]}\end{array}$ & Symbol & \# Exp. & \# Drop. \\
\hline 1 & 63.6 & 0 & 36.4 & $5-10$ & $\times$ & 16 & 16 \\
2 & 53.8 & 0 & 46.2 & $1-10$ & + & 28 & 28 \\
3 & 32.2 & 13.8 & 54.0 & 10 & $*$ & 22 & 5 \\
4 & 38.3 & 7.6 & 54.1 & 10 & $\bullet$ & 16 & 4 \\
\hline
\end{tabular}

number of molecules which may evaporate during that time is negligible to the total number of molecules in the condensed phase. This was confirmed by checking the melting points of the droplets after freezing which were found to be in agreement with the phase diagram. After sealing the droplets against ambient air with a second plate, the droplet cell was placed on a temperature stage attached to a Confocal Raman Microscope (see Fig. 3). In this setup the droplets' temperature can be varied between 170-295 K. The temperature was calibrated by measuring the melting points of heptane $(182.55 \mathrm{~K})$, octane $(216.35 \mathrm{~K})$, decane $(243.45 \mathrm{~K})$, dodecane $(263.5 \mathrm{~K})$, and water $(273.15 \mathrm{~K})$ in the cell. Phase changes (i.e. freezing or melting) are observed visually with the microscope part of the setup. In addition, the crystalline solids formed upon freezing were identified by Raman spectroscopy using a Nd:YAG-laser at a wavelength of $532 \mathrm{~nm}$ for illumination. The backscattered light is reflected onto a grating $\left(1800 \mathrm{~mm}^{-1}\right)$ and focused on the CCD detector of the spectrograph. The resulting spectral resolution is about $2-4 \mathrm{~cm}^{-1}$ within the observed range of $500-4500 \mathrm{~cm}^{-1}$. Figure 4 shows Raman spectra of droplets $\left(10^{-2} \mathrm{~cm}^{3}\right)$ with an $\mathrm{HNO}_{3}: \mathrm{H}_{2} \mathrm{O}$ mole ratio of $1: 2$ and $1: 3$ corresponding to the stoichiometry of NAD and NAT, respectively. In each case the spectra were recorded during a cooling cycle (red spectra) and a warming cycle (blue spectra) at about the same temperature. To avoid any possible temperature bias the droplets were not illuminated by laser light during the course of the freezing experiments reported below. Spectra were taken only after the droplets were frozen. Table 1 shows the composition, volume, total number of different performed experiments, and total number of individual droplets. The droplets were prepared from stock solutions which were titrated against a $1 \mathrm{M} \mathrm{NaOH}$ solution. In an experimental run the droplets were cooled at a rate of $d T / d t=-10 \mathrm{~K} \mathrm{~min}^{-1}$ until nucleation occurred. The ternary solution droplets (solution 3 and 4, Table 1) did not freeze above $178 \mathrm{~K}$ during such runs. Hence, the temperature in these experiments was decreased stepwise (by 5-10 K) keeping the temperature constant for several minutes after each step. All experiments were recorded on tape together with the experimental time

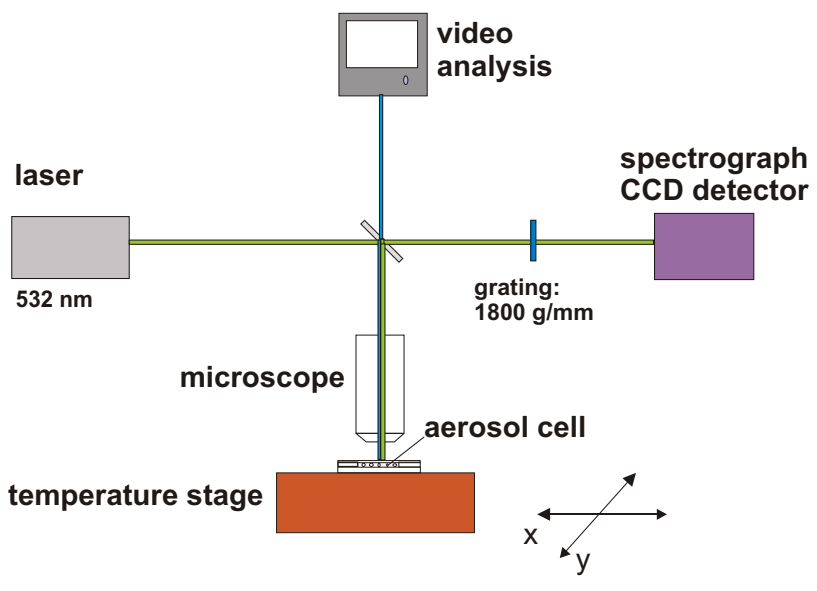

Fig. 3. Sketch of the experimental setup.

and droplet temperature. The video tapes were analyzed afterwards to determine the number of nucleation events, $n$, as a function of time and temperature. The upper limit of the homogeneous nucleation rate coefficient $J_{\text {hom }}^{\text {up }}$ can be derived from the experimental data using the following formula:

$J_{\text {hom }}^{\text {up }}(T)=\frac{n^{*}}{\sum_{i} V_{i} \cdot t_{i}(T)}$,

where $t_{i}(T)=\int_{T}^{T_{i}^{*}}\left(d T^{\prime} / d t\right)_{i}^{-1} d T^{\prime}$ is the time interval that the $i$ th droplet with volume $V_{i}$ remained liquid between $T$ and $T_{i}^{*} . T_{i}^{*}$ is either the nucleation temperature of the droplet or the lowest investigated temperature, and $(d T / d t)_{i}$ is the cooling rate applied in the particular experiment. $n^{*}$ is the upper fiducial limit of $n$ determined by Poisson statistics at a confidence level of 0.999 (Koop et al., 1997), i.e. if the experiments were repeated an infinite number of times the observed number of nucleation events will be smaller than $n^{*}$ in $99.9 \%$ of the cases. Equation (4) yields a conservative (i.e. the highest possible) $J_{\text {hom-value, which is in agreement }}$ with the experimental data.

In detail, Eq. (4) is conservative for the following reasons: First, the time interval, $t_{i}(T)$, that a droplet stays liquid below 
$T$ is always smaller than the time interval it would stay liquid at $T$ (assuming that $J_{\text {hom }}$ monotonically increases with decreasing temperature in the investigated temperature range). Second, instead of using the actual number of nucleation events, $n$, we employed $n^{*}$, which represents a conservative value for $n$ because $n^{*}>n$ in all cases. Third, it cannot be ruled out that heterogeneous nucleation of NAD and NAT occurred in the large droplets. Even in this case, the observed nucleation rate is always an upper limit for the homogeneous nucleation rate, independently of whether heterogeneous nucleation occurred or not. All experimental data were analyzed using Eq. (4). The derived $J_{\text {hom }}^{\text {up }}$-values were used to calculate lower limits of the activation energy, $\Delta G_{\text {act }}^{\text {low }}$, according to Eq. (3).

\section{Results and discussion}

In Fig. 5 the resulting $\Delta G_{\text {act }}$-values are shown as function of temperature and saturation ratio. The different symbols in Fig. 5 correspond to those in Table 1. In addition, we have reanalyzed published bulk experiments (Koop et al., 1995, 1997) to determine the upper limit for $J_{\text {hom }}$ according to $J_{\text {hom }}^{\text {up }}(T)=n^{*} /(V \cdot t)$, where $n^{*}$ is the same as above, $V$ is the volume of the solution, and $t$ is the time the solution remained liquid at temperature $T$ (Koop et al., 1997). The corresponding $\Delta G_{\text {act }}^{\text {low }}$-values were obtained using Eq. (3) and are shown as open symbols in Fig. 5. The solid symbols in Fig. 5 represent the same data as in Fig. 1.

Furthermore, we have added the aerosol nucleation data by Bertram et al. (2000). We note, that we have used a nucleation rate coefficient of $J=4.4 \times 10^{9} \mathrm{~cm}^{-3} \mathrm{~s}^{-1}$ for these data, slightly lower than the one in the original publication (A. K. Bertram, personal communication). Figure 5 clearly reveals that the newly derived $\Delta G_{\text {act-values are sig- }}$ nificantly higher than the linear extrapolation formulation at stratospheric conditions. Since our data points are lower limits of $\Delta G_{\text {act }}$ (thus, upper limits of $J_{\text {hom }}$ ) the actual values of $\Delta G_{\text {act }}$ are likely to be even higher than those shown in Fig. 5. Clearly, the linear extrapolation used in Tabazadeh et al. (2001) is not in agreement with our new droplet data nor with bulk experiments published previously. In the following, we use the combined experimental data (Koop et al., 1995, 1997; Bertram and Sloan, 1998a,b; Bertram et al., 2000; Salcedo et al., 2001, and this work) to derive upper homogeneous nucleation rate coefficients of NAD and NAT at stratospheric conditions. Figure 6a shows the composition and corresponding NAD and NAT saturation ratios of STS droplets at $50 \mathrm{mbar}$ (approx. $20 \mathrm{~km}$ altitude) for mixing ratios of 5 ppmv $\mathrm{H}_{2} \mathrm{O}, 10$ ppbv $\mathrm{HNO}_{3}$, and 0.5 ppbv $\mathrm{H}_{2} \mathrm{SO}_{4}$ (Carslaw et al., 1994). In Fig. 6b, NAD and NAT nucleation rate coefficients are shown for the conditions displayed in panel (a). In the region of highest saturation ratios (shaded region in Fig. 6) circles and squares represent maximum nucleation rate coefficients derived from experimental data as
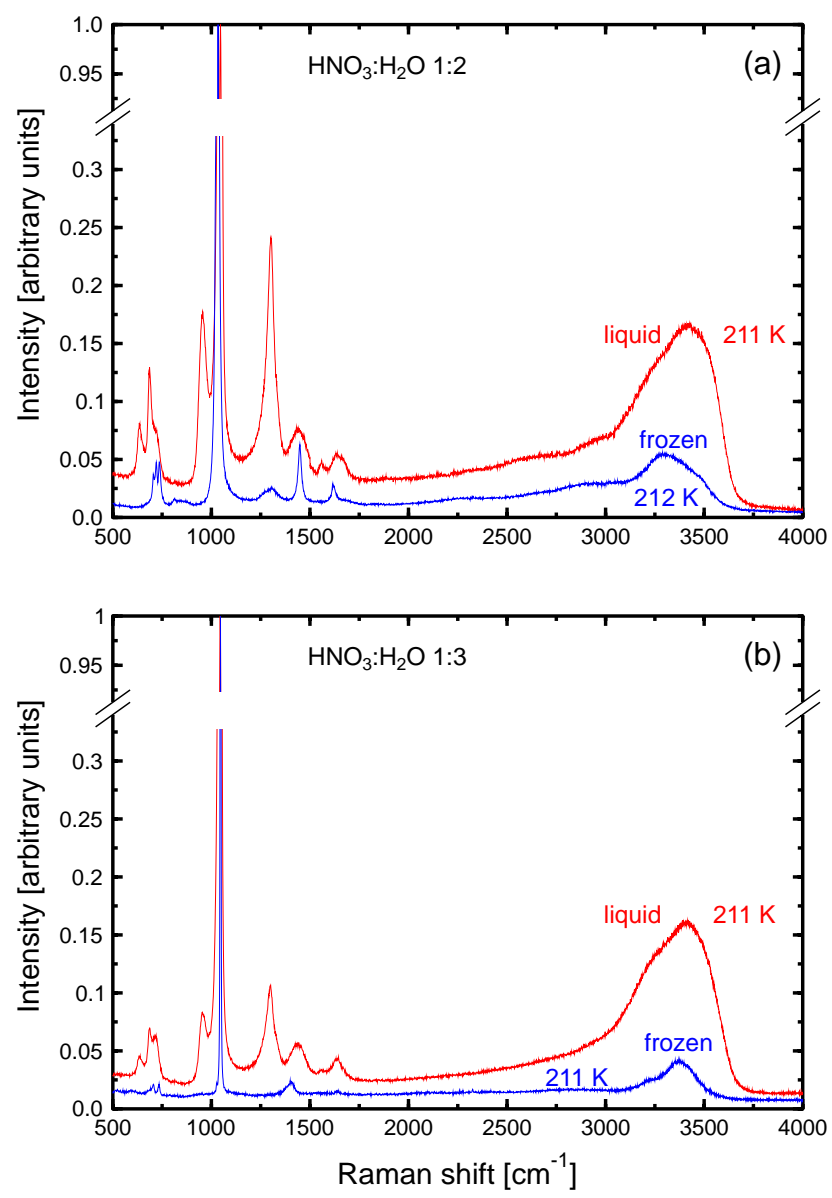

Fig. 4. Raman spectra of droplets with a volume of $10^{-2} \mathrm{~cm}^{3}$. (a) Red line: spectrum of a liquid droplet with a $\mathrm{HNO}_{3}: \mathrm{H}_{2} \mathrm{O}$ mole ratio of 1:2 at $211 \mathrm{~K}$; blue line: spectrum of a frozen droplet at $212 \mathrm{~K}$. (b) Red line: spectrum of a liquid droplet with a $\mathrm{HNO}_{3}: \mathrm{H}_{2} \mathrm{O}$ mole ratio of $1: 3$ at $211 \mathrm{~K}$; blue line: spectrum of a frozen droplet at $211 \mathrm{~K}$. The spectra are normalized with respect to the $v_{1}\left(\mathrm{NO}_{3}^{-}\right)$vibration band at $\sim 1040 \mathrm{~cm}^{-1}$.

follows: In Fig. 5 for one temperature (e.g. 191.5 K) all data points are selected by color, and then interpolated as function of saturation ratio using $S_{\mathrm{NAX}}$ read off Fig. 6a. From the $\Delta G_{\text {act }}$-value obtained in this way we derive $J_{\text {hom }}^{\text {up }}$ using Eq. (1). Blue and red arrows mark the temperature where $S_{\mathrm{NAD}}=1$ and $S_{\mathrm{NAT}}=1$, respectively, i.e. where the nucleation rate coefficients must decrease to zero. Solid lines in Fig. $6 \mathrm{~b}$ represent homogeneous nucleation rate coefficients calculated using the formulation of Tabazadeh et al. (2001). Figure $6 \mathrm{c}$ shows the corresponding NAD and NAT particle production rates for the conditions displayed in panel (a) using the nucleation rate coefficients shown in panel (b). Solid lines are calculated with the equations given by Tabazadeh et al. (2001) taking into account that the total aerosol volume increases with decreasing temperature (Carslaw et al., 1994). Stars are values taken directly from Fig. 1 in Tabazadeh et al. 

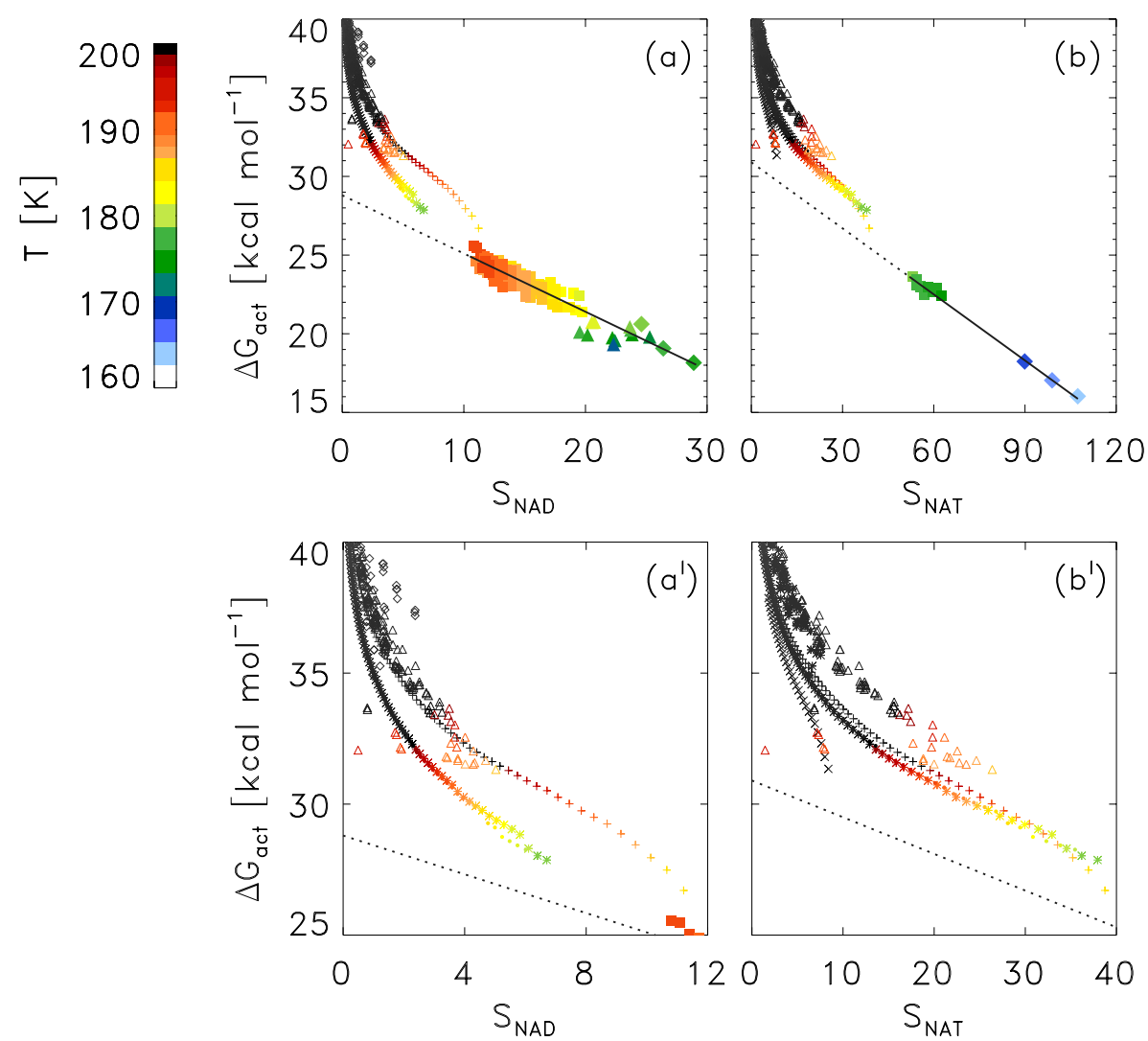

Fig. 5. $\Delta G_{\text {act }}$ as function of the NAD and NAT saturation ratios derived from laboratory nucleation data using Eq. (3). Large droplet data: $\times$ : $63.6 \mathrm{wt} \% \mathrm{HNO}_{3}$; +: $53.8 \mathrm{wt} \% \mathrm{HNO}_{3} ; *: 32.2 \mathrm{wt} \% \mathrm{HNO}_{3}$ and $13.8 \mathrm{wt} \% \mathrm{H}_{2} \mathrm{SO}_{4} ; \bullet: 38.3 \mathrm{wt} \% \mathrm{HNO}_{3}$ and $7.6 \mathrm{wt} \% \mathrm{H}_{2} \mathrm{SO}_{4}($ all this work). Bulk solution data: $\triangle$ : binary $\mathrm{HNO}_{3} / \mathrm{H}_{2} \mathrm{O}$ solutions of varying composition (Koop et al., 1997). $\diamond:$ ternary $\mathrm{HNO}_{3} / \mathrm{H}_{2} \mathrm{SO}_{4} / \mathrm{H}_{2} \mathrm{O}$ solutions of varying composition (Koop et al., 1995, 1997). Aerosol data: (a) $\mathbf{\square}: 57 \mathrm{wt} \%, 60 \mathrm{wt} \%$, and $64 \mathrm{wt}^{2} \mathrm{HNO}_{3}$ (Salcedo et al., 2001); $\checkmark: 64$ wt $\% \mathrm{HNO}_{3}$ (Bertram and Sloan, 1998a); $\mathbf{\Delta}$ : binary $\mathrm{HNO}_{3} / \mathrm{H}_{2} \mathrm{O}$ aerosol of varying composition (Bertram et al., 2000). (b) $\mathbf{\square}$ : 54 wt\% $\mathrm{HNO}_{3}$ (Salcedo et al., 2001); $54 \mathrm{wt} \% \mathrm{HNO}_{3}$ (Bertram and Sloan, 1998b). The color coding indicates at which temperature the data were obtained. The solid lines indicate the linear relationship between $\Delta G_{\text {act }}$ and $S_{\mathrm{NAX}}$ observed by Salcedo et al. (2001), and the dotted lines are the linear extrapolations to stratospheric conditions used in Tabazadeh et al. (2001). (a') and (b') show an enlarged view of the top left corner of panels (a) and (b), respectively.

(2001). The circles and squares represent the production rates calculated using the experimentally derived upper nucleation rate coefficients shown in Fig. 6b. Figure $6 \mathrm{c}$ reveals that the maxima of the resulting production rates of the formulation by Tabazadeh et al. (2001) (solid lines) are too large by a factor of $10^{8}$ for NAD and $10^{4}$ for NAT when compared to the experimentally derived production rates.

\section{Conclusions}

Salcedo et al. (2001) have investigated the nucleation of NAD and NAT from binary aqueous nitric acid droplets. We consider their experimental data to be sound and the observed linear relationship between the activation energy, $\Delta G_{\text {act }}$, and the respective nitric acid hydrate saturation ratio, $S_{\mathrm{NAX}}$, to be valid in the experimentally observed range of saturation $\operatorname{ratios}\left(S_{\mathrm{NAD}}=11-30, S_{\mathrm{NAT}}=52-107\right)$. However, the theoretical arguments and experimental data presented above show that the linear relationship between $\Delta G_{\text {act }}$ and $S_{\text {NAX }}$ is not valid at stratospheric saturation ratios. Therefore, the linear relationship must not be used in microphysical models of PSCs.

The analysis of experimental data presented above shows homogeneous NAD and NAT nucleation rate coefficients to be exceedingly low $\left(<2 \times 10^{-5} \mathrm{~cm}^{-3} \mathrm{~s}^{-1}\right.$ and $<8 \times$ $10^{-2} \mathrm{~cm}^{-3} \mathrm{~s}^{-1}$, respectively) in STS aerosols under polar stratospheric conditions, in agreement with earlier studies (Koop et al., 1995, 1997). These nucleation rate coefficients are smaller by orders of magnitude than those used in a recent modelling study of stratospheric denitrification (Tabazadeh et al., 2001). In that study, it was asserted that homogeneous NAD and NAT nucleation from STS aerosols is sufficient to explain the denitrification observed in the Arctic and Antarctic stratosphere. NAT particle number densities that are 


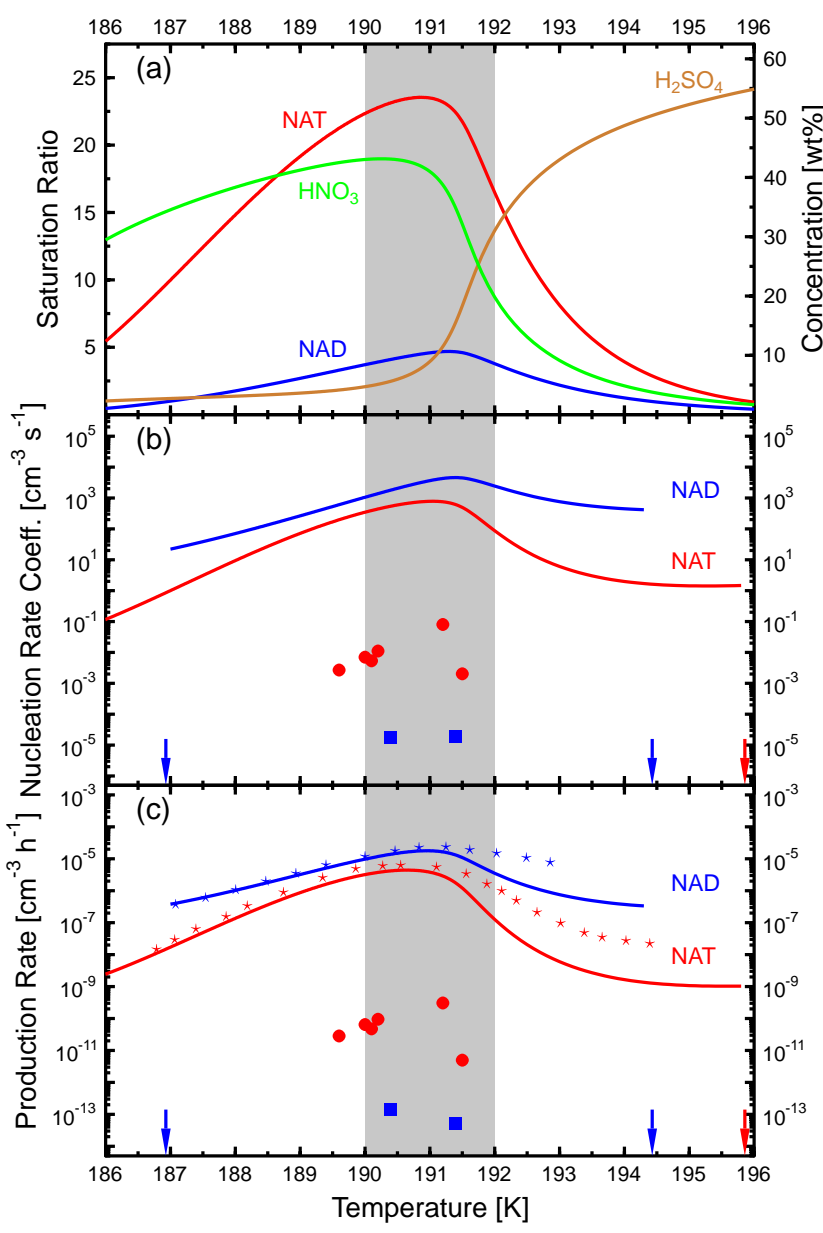

Fig. 6. (a) The composition (green and orange lines) and the saturation ratios (red and blue lines) of STS aerosols as a function of temperature at 50 mbar with 5 ppmv $\mathrm{H}_{2} \mathrm{O}, 10$ ppbv $\mathrm{HNO}_{3}$, and 0.5 ppbv $\mathrm{H}_{2} \mathrm{SO}_{4}$ (Carslaw et al., 1994). The shaded region indicates the temperature range where the $S_{\mathrm{NAX}}$-values have their maximum. (b) Upper limits for the nucleation rate coefficients of NAD (squares) and NAT (circles) in STS droplets, derived from experimental data for the conditions shown in panel (a). For comparison, solid lines indicate the homogeneous nucleation rate coefficient in STS droplets for the same conditions calculated using the formulation of Tabazadeh et al. (2001). (c) Hourly production rates of NAD and NAT particles (squares and circles, respectively) per $\mathrm{cm}^{3}$ of air derived from the nucleation rate coefficients shown in panel (b). The increase of the total aerosol volume with decreasing temperature was taken into account (Carslaw et al., 1994). Also shown as solid lines are the NAD and NAT production rates for the same conditions calculated using the formulation of Tabazadeh et al. (2001). Stars show values for similar conditions taken directly from Fig. 1 of Tabazadeh et al. (2001). (We note that we can reproduce the stars by assuming a constant total aerosol volume of $5.9 \times 10^{-12} \mathrm{~cm}^{3}$.) Arrows in (b) and (c) mark the temperature where the saturation ratio of NAD (blue) and NAT (red) equals one.

in agreement with recent field observations $\left(\sim 10^{-4} \mathrm{~cm}^{-3}\right.$, Fahey et al., 2001) were obtained by converting all NAD particles into NAT particles in the simulation. This was achieved by adding the NAD and NAT homogeneous nucleation rate coefficients. The corresponding particle production rates were about $\sim 10^{-5} \mathrm{~cm}^{-3}$ (air) $\mathrm{h}^{-1}$. In contrast, using the upper limits for the particle production rates (Fig. 6c) derived in this study and assuming the maximum saturation ratios to persist for two months, we arrive at particle number densities of $\sim 5 \times 10^{-7} \mathrm{~cm}^{-3}$, much smaller than reported by Fahey et al. (2001). Furthermore, Tabazadeh et al. (2001) state that NAT particle production rates smaller than $\sim 10^{-5} \mathrm{~cm}^{-3}$ (air) $\mathrm{h}^{-1}$ are unimportant to denitrification. Even if we combine the NAD and NAT production rates of Fig. $6 \mathrm{c}$ the maximum possible value in agreement with the laboratory data is only $\sim 3 \times 10^{-10} \mathrm{~cm}^{-3}$ (air) $\mathrm{h}^{-1}$. This clearly shows that homogeneous nucleation of NAD and NAT from liquid supercooled ternary solution aerosols cannot explain the observed polar denitrification. Therefore, other NAD/NAT formation mechanisms such as heterogeneous NAT nucleation on ice particles are required to explain polar denitrification (Waibel et al., 1999).

Acknowledgements. We are grateful to D. Salcedo and A. K. Bertram for providing original experimental data sets. Internal funding through an ETH grant is gratefully acknowledged.

\section{References}

Anthony, S. E., Onash, T. B., Tisdale, R. T., Disselkamp, R. S., Tolbert, M. A., and Wilson, J. C.: Laboratory studies of ternary $\mathrm{HNO}_{3} / \mathrm{H}_{2} \mathrm{SO}_{4} / \mathrm{H}_{2} \mathrm{O}$ particles: Implications for polar stratospheric cloud formation, J. Geophys. Res., 102, 10777-10 784, 1997.

Bertram, A. K. and Sloan, J. J.: Temperature-dependent nucleation rate constants and freezing behavior of submicron nitric acid dihydrate aerosol particles under stratospheric conditions, J. Geophys. Res., 103, 3553-3561, 1998a.

Bertram, A. K. and Sloan, J. J.: The nucleation rate constants and freezing mechanism of nitric acid trihydrate aerosol under stratospheric conditions, J. Geophys. Res., 103, 13 261-13 265, 1998 b.

Bertram, A. K., Dickens, D. B., and Sloan, J. J.: Supercooling of type 1 polar stratospheric clouds: The freezing of submicron nitric acid aerosols having $\mathrm{HNO}_{3}$ mole fractions less than 0.5, J. Geophys. Res., 105, 9283-9290, 2000.

Carslaw, K. S., Luo, B. P., Clegg, S. L., Peter, Th., Brimblecombe, P., and Crutzen, P. J.: Stratospheric aerosol growth and $\mathrm{HNO}_{3}$ gas phase depletion from coupled $\mathrm{HNO}_{3}$ and water uptake by liquid particles, Geophys. Res. Lett., 21, 2479-2482, 1994.

Fahey, D. W., Gao, R. S., Carslaw, K. S., Kettleborough, J., Popp, P. J., Northway, M. J., Holecek, J. C., Ciciora, S. C., McLaughlin, R. J., Thompson, T. L., Winkler, R. H., Baumgardner, D. G., Gandrud, B., Wennberg, P. O., Dhaniyala, S., McKinney, K., Peter, T., Salawitch, R. J., Bui, T. P., Elkins, J. W., Webster, C. R., Atlas, E. L., Jost, H., Wilson, J. C., Herman, R. L., Kleinböhl, A., and von König, M.: The Detection of Large $\mathrm{HNO}_{3}$-Containing Particles in the Winter Arctic Stratosphere, Science, 291, 10261030, 2001. 
Koop, T., Biermann, U. M., Raber, W., Luo, B. P., Crutzen, P. J., and Peter, Th.: Do stratospheric aerosol droplets freeze above the ice frost point?, Geophys. Res. Lett., 22, 917-920, 1995.

Koop, T., Luo, B. P., Biermann, U. M., Crutzen, P. J., and Peter, T.: Freezing of $\mathrm{HNO}_{3} / \mathrm{H}_{2} \mathrm{SO}_{4} / \mathrm{H}_{2} \mathrm{O}$ Solutions at Stratospheric Temperatures: Nucleation Statistics and Experiments, J. Phys. Chem. A, 101, 1117-1133, 1997.

MacKenzie, A. R.: Are the (Solid-Liquid) Kelvin Equation and the Theory of Interfacial Tension Components Commensurate?, J. Phys. Chem. B, 101, 1817-1823, 1997.

Salcedo, D., Molina, T., and Molina, M. J.: Homogeneous Freezing of Concentrated Aqueous Nitric Acid Solutions at Polar Stratospheric Temperatures, J. Phys. Chem. A, 105, 1433-1439, 2001.

Schreiner, J., Voigt, C., Kohlmann, A., Arnold, F., Mauersberger, K., and Larson, N.: Chemical Analysis of Polar Stratospheric Cloud Particles, Science, 283, 968-970, 1999.

Tabazadeh, A., Jensen, E. J., Toon, O. B., Drdla, K., and Scheberl,
M. R.: Role of the Stratospheric Polar Freezing Belt in Denitrification, Science, 291, 2591-2594, 2001.

Tolbert, M. A. and Toon, O. B.: Solving the PSC Mystery, Science, 292, 61-63, 2001.

Voigt, C., Schreiner, J., Kohlmann, A., Zink, P., Mauersberger, K., Larsen, N., Deshler, T., Kröger, C., Rosen, J., Adriani, A., Cairo, F., di Donfrancesco, G., Viterbini, M., Ovarlez, J., Ovarlez, H., David, C., and Dörnback, A.: Nitric Acid Trihydrate (NAT) in Polar Stratospheric Clouds, Science, 290, 1756-1758, 2000.

Waibel, A. E., Peter, Th., Carslaw, K. S., Oelhaf, H., Wetzel, G., Crutzen, P. J., Pöschl, U., Tsias, A., Reimer, E., and Fischer, H.: Arctic Ozone Loss Due to Denitrification, Science, 283, 2064 2069, 1999.

Worsnop, D. R., Fox, L. E., Zahniser, M. S., and Wofsy, S. C.: Vapor Pressures of Solid Hydrates of Nitric Acid: Implications for Polar Stratospheric Clouds, Science, 259, 71-74, 1993. 